\title{
Cluster Headache - Incidence and Its Association with Age, Gender and Triggers
}

\author{
Abinayaah Suresh ${ }^{1}$, Gitanjali Narendran², Sambandhan Alandur Paramasivan³ ${ }^{3}$ Haribalan Lakshmanasamy ${ }^{4}$ \\ ${ }^{1}$ Department of ENT, Sri Muthukumaran Medical College Hospital \& Research Institute, Affiliated to \\ Tamilnadu MGR Medical University, Chikkarayapuram, Chennai, Tamilnadu, India. ${ }^{2,3,4}$ Department of \\ Otorhinolaryngology, Sri Muthukumaran Medical College Hospital \& Research Institute, Affiliated to \\ Tamilnadu MGR Medical University, Chikkarayapuram, Chennai, Tamilnadu, India.
}

ABSTRACT

\section{BACKGROUND}

Cluster headache is an unusual but particularly painful and crippling primary headache disorder with a prevalence of 1 in 1000 making study of the disease process a difficult task to master. These headaches are always unilateral characterised by recurrent short-lasting attacks of 15 - 180 minutes associated with ipsilateral autonomic signs. The diagnosis is mainly clinical, and it continues to be managed sub optimally as the chance of coming across such a condition is few and far between. This study was conducted to determine the incidence of cluster headache in a hospital population and study its association with age, gender and triggers.

\section{METHODS}

This is a cross sectional study of a total of 100 patients attending our Otorhinolaryngology department from June 2017 to June 2018 at Sri Muthukumaran Medical College Hospital \& Research Centre with primary complaints of headache. Prior ethical committee clearance was obtained. Patients with chronic debilitating illness, chronic rhino sinusitis, headache following trauma or the presence of fever or any other acute illness were excluded from this study. The results were interpreted using Statistical Package for Social Sciences (SPSS) version 17.

\section{RESULTS}

Out of the total number of 100 patients with headache, only one patient, a 40 -yearold male was diagnosed with cluster headache.

\section{CONCLUSIONS}

Hence, we conclude that the incidence of cluster headache in the total of 100 patients is only $1 \%$ which makes it a quite rare condition. Diagnosis is clinical, hence effective history taking is mandatory.

\section{KEY WORDS}

Cluster Headache, Primary Headache, Trigeminal Autonomic Cephalgia, Cluster Attacks
Corresponding Author:

Abinayaah Suresh,

Assistant Professor,

Department of ENT,

Sri Muthukumaran Medical College

Hospital \& Research Institute,

Affiliated to Tamilnadu

Dr. MGR Medical University,

Chikkarayapuram, Chennai, India.

E-mail:abin004doc@gmail.com

DOI: $10.14260 / j e m d s / 2021 / 130$

How to Cite This Article:

Suresh A, Narendran G, Paramasivan SA, et al. Cluster headache - incidence and its association with age, gender and triggers. J Evolution Med Dent Sci 2021;10(09):604607, DOI: $10.14260 /$ jemds/2021/130

Submission 21-10-2020,

Peer Review 23-12-2020,

Acceptance 30-12-2020,

Published 01-03-2021.

Copyright (c) 2021 Abinayaah Suresh et al. This is an open access article distributed under Creative Commons Attribution License [Attribution 4.0 International (CC BY 4.0)] 


\section{BACKGROUND}

Headache disorders being one of the most commonly occurring conditions, have a prevalence of about $48.9 \%$ in the general population. ${ }^{1}$ More than $90 \%$ of the population have experienced headache at least once in their lifetime.

The reasons can be dehydration, lack of sleep, caffeine withdrawals, improper nutrition, visual disturbances or a brain tumour or simply without any obvious cause. Primary headaches involve headache disorders that causes repeated and persistent pain without any clear underlying pathology. Trigeminal autonomic cephalgias are a category of primary headache disorders which is phenotypically well characterised.

Cluster headache is one such disorder which comes under 'idiopathic headache entities' which is an unusual and severe 'primary headache disorder' with distinct characteristics comprising of severe unilateral headache occurring in typical bouts or 'clusters' with each attack lasting for 15 - 180 minutes more frequently over the orbital and supraorbital area accompanied by ipsilateral autonomic signs.

Having said to be one of the most painful conditions and the pain being described as 'suicidal and tearing', these so called 'cluster sufferers' keep visiting the ENT, ophthalmology and maxillofacial departments with many years of profound suffering before arriving to this particular diagnosis. The events usually occur once or twice a day for weeks to months with characteristic feature of remission (usually months to years). The pain is always unilateral around the periorbital area accompanied with ipsilateral autonomic signs such as lacrimation, nasal congestion, ptosis, miosis, flushing of the face, lid oedema and redness of the eye. The prevalence is estimated to around $0.5-1 / 1000$. Smoking and alcohol are said to be the most common triggers for this. Diagnosis is mainly clinical. Hence a thorough history and physical examination is essential in diagnosing cluster headaches. A questionnaire about the type, duration and associated autonomic signs has a sensitivity of $81 \%$ and specificity of $100 \%$.

Cluster headache presents in two different ways. The most common presentation is an episodic one where the patient presents with bouts lasting for more than a week with periods of remissions lasting for more than 4 weeks. Chronic cluster headache $(\mathrm{CH})$ is a much rare phenomenon which might arise from a pre-existing episodic type or can start afresh. The absence of remission periods for within a year or remissions lasting less than a month is the hallmark of a chronic variety. ${ }^{2}$

Circannual periodicity is specific for cluster headache where the attacks recur in a fixed pattern during a specific time of the year. 3,4

Hence effective history taking is worthwhile and is integral to make a correct diagnosis with a vast majority of patients requiring no special investigations. ${ }^{1}$

\section{METHODS}

This is a cross sectional study of a total number of 100 patients attending the otorhinolaryngology department from June 2017 to June 2018 at Sri Muthukumaran Medical College
Hospital \& Research Institute after the ethical committee approved the study protocol.

The study was conducted after taking prior ethical committee clearance and consent from the patients regarding the study. We included patients attending the otorhinolaryngology outpatient department with chief complaints of headache who were above 18 years of age and ready to participate in the study. Patients below 18 years of age, patients with any chronic debilitating illness, chronic rhino sinusitis, post traumatic headache, presence of fever or any infection or any acute illness or patients who have not consented for the study were excluded. A prior informed and written consent was obtained before recording the details.

A thorough history taking about the type, quality, duration, laterality and severity of the headache was noted. All patients were subjected to a diagnostic nasal endoscopy, fundus examination and electroencephalogram. Computed tomography scan of the brain and x-ray of the paranasal sinuses were done in cases required. If needed a psychiatric assessment was also done.

The analysis and interpretation of the statistics was done with Statistical Package for Social Sciences (SPSS) version 17.

\section{RESULTS}

The incidence of cluster headache in a of a total number of 100 patients attending the otorhinolaryngology department at Sri Muthukumaran Medical College Hospital \& Research Institute was found to be 1 in 100 which clearly shows its rarity.

In our study, only one out of 100 patients, aged 39 was diagnosed with cluster headache. The diagnosis was done as stated by the International Classification of Headache Disorders (ICHD) II criteria.

\begin{tabular}{|ccccc|}
\hline Age Group & Frequency & Percent & Valid Percent & $\begin{array}{c}\text { Cumulative } \\
\text { Percent }\end{array}$ \\
\hline Valid $\leq$ 20 years & 5 & 5.0 & 5.0 & 5.0 \\
21 - 40 years & 64 & 64.0 & 64.0 & 64.0 \\
$>$ 40 years & 31 & 31.0 & 31.0 & 31.0 \\
Total & 100 & 100.0 & 100.0 & \\
\hline Table 1. Age Distribution amongst 100 Patients Attending the
\end{tabular}

Otorhinolaryngology Department during the Study Period

\begin{tabular}{|ccccc|}
\hline Sex & Frequency & Percent & Valid Percent & $\begin{array}{c}\text { Cumulative } \\
\text { Percent }\end{array}$ \\
\hline Valid male & 64 & 64.0 & 64.0 & 64.0 \\
Female & 36 & 36.0 & 36.0 & 100.0 \\
Total & 100 & 100.0 & 100.0 & \\
\hline \multicolumn{4}{|c|}{$\begin{array}{c}\text { Table 2. Gender Distribution amongst the 100 Patients } \\
\text { Who Came with Chief Complaint of Headache }\end{array}$} \\
\hline \multicolumn{4}{|c}{} \\
\hline
\end{tabular}

\begin{tabular}{|ccccc|}
\hline Triggers & Frequency & Percent & Valid Percent & $\begin{array}{c}\text { Cumulative } \\
\text { Percent }\end{array}$ \\
Valid alcohol & 18 & 18.0 & 18.0 & 18.0 \\
Alcohol / solvents & 1 & 1.0 & 1.0 & 19.0 \\
Alcohol / smoking & 1 & 1.0 & 1.0 & 20.0 \\
Lack of sleep & 5 & 5.0 & 5.0 & 25.0 \\
Nil & 61 & 61.0 & 61.0 & 86.0 \\
Paint & 2 & 2.0 & 2.0 & 88.0 \\
Solvents & 8 & 8.0 & 8.0 & 96.0 \\
Stress & 4 & 4.0 & 4.0 & 100.0 \\
Total & 100 & 100.0 & 100.0 \\
\hline Table 3. Association of Headache with Various Relatable Triggers \\
amongst 100 Patients Attending the Otorhinolaryngology Department \\
during the Study Period \\
\multicolumn{5}{|c}{} \\
\hline \multicolumn{5}{c}{}
\end{tabular}




\begin{tabular}{|ccccc|}
\hline $\begin{array}{c}\text { H / O } \\
\text { Smoking }\end{array}$ & Frequency & Percent & Valid Percent & $\begin{array}{c}\text { Cumulative } \\
\text { Percent }\end{array}$ \\
Valid YES & 30 & 30.0 & 30.0 & 30.0 \\
NO & 70 & 70.0 & 70.0 & 100.0 \\
Total & 100 & 100.0 & 100.0 \\
\hline $\begin{array}{r}\text { Table 4. Relationship between Smoking and Headache-Incidence } \\
\text { among 100 Patients Attending the Otorhinolaryngology Department } \\
\text { during the Study Period }\end{array}$ \\
\hline \multicolumn{5}{|c}{} \\
\hline
\end{tabular}

\begin{tabular}{|ccccc|}
\hline $\begin{array}{c}\text { Type of } \\
\text { Headache } \\
\text { Valid cluster } \\
\text { headache }\end{array}$ & Frequency & Percent & Valid Percent & $\begin{array}{c}\text { Cumulative } \\
\text { Percent }\end{array}$ \\
Migraine & 2 & 1.0 & 1.0 & 1.0 \\
$\mathrm{Tt}$ & 53 & 2.0 & 2.0 & 3.0 \\
$\mathrm{Nil}$ & 44 & 44.0 & 53.0 & 56.0 \\
Total & 100 & 100.0 & 100.0 & 100.0 \\
\hline Table 5. Incidence of Cluster Headache amongst 100 \\
Patients Attending the Otorhinolaryngology \\
Department during the Study Period
\end{tabular}

The number of cluster attacks per day ranged from $1-3$ to 1 - 5 times / day. Duration of the cluster episode lasted 30 minutes to one hour most of the times and was also severe pricking type of pain. The attacks were associated with sweating of one side of the face with flushing of the face and redness of the eye on the same side. He was a chronic smoker and had the habit of smoking 5 - 10 cigarettes per day for the past 20 years. He was also working on night shifts and complained of sleep disturbances occasionally.

\section{DISCUSSION}

Studies conducted in various countries including India stated that the incidence is just $0.1 \%$ of the entire population making the diagnosis of one such condition a tough one. ${ }^{1}$

A study by Almeida proclaims that the prevalence of cluster headache was found to be $0.1 \%$ in Denmark; $0.09 \%$ in Sweden and $0.07 \%$ in the Republic of San Marino. ${ }^{5}$ The prevalence of cluster headache was estimated to be $0.0414 \%$ in the city of Barbacena, Brazil. ${ }^{6}$

The age of occurrence of the first episode of $\mathrm{CH}$ is usually after adolescence more marked between the ages 20 to 40 . However, females have a much earlier onset compared to males which may have been said to be because of the influence of hormones. ${ }^{4}$

Bhargava et al. series 2014 stated that the mean age of incidence of trigeminal autonomic cephalgias was around 28 - 55 years of age (33.8 years). ${ }^{7}$

The mean age of onset seems to be higher in the Asian countries compared to Western countries. Friedman series of 1954 stated 28.0 years as the mean age of onset, whereas in Ekbom et al. series of 2002 it was 27.5 years, 29.6 in that of Kundrow et al. series of $1987.8,9,10$

As far as gender is concerned, earlier studies showed a higher incidence in males when compared to females, however recent studies indicate almost an equal prevalence among both genders. Women also seem to present with superimposing migraine like features which makes the diagnosis and their further management difficult.

Rozen et al. series of 2001 states a slight male predominance, which may be attributed to the influence of male sex hormones, consumption of more alcohol or smoking or men are believed to undergo more stress compared to women. However, the study also states that the incidence seems to be increasing in women if they undergo the same levels of stress and engaging in the same amount of vices as men. ${ }^{4}$ A very recent study of Peng et al. series of 2020 concluded that there was a stronger male predominance amongst Asian populations compared to European and North American populations. ${ }^{11}$ In India also it is still the male population with the higher incidence when compared to the west in accordance to other studies. ${ }^{11}$

\section{Triggers}

Most headaches can have causes that are not due to underlying diseases. Identifying a trigger is always not easy. However, many previous studies have found to have a close link between the incidence of cluster headache with alcohol and smoking. Alcohol is said to be the number one trigger in majority of cases. ${ }^{1}$ Smoking (both active \& passive) not only acts as a trigger in bringing about an episode of $\mathrm{CH}$ but also the severity, frequency and response to medications are much altered in smokers compared to non-smokers.

Apart from these triggers, obesity; unhealthy lifestyle; use of illicit drugs; lack of physical activity and depression have also been considered as additional risk factors.

The presence of comorbidities also holds the physician from generously prescribing medications as the drugs need to be carefully tailored in various chronic conditions hence limiting the outcomes.

\section{Role of Hormones}

The onset of the first episode is seemingly much earlier in women which could be attributed to the influence of female sex hormones. Marta Allena et al. series of 2019 have reported the occurrence of 'cluster bouts' in female patients during periods of abrupt fluctuations of sex hormones. ${ }^{8,12,13}$

\section{Migraine vs. Cluster Headache}

$\mathrm{CH}$ and migraine present in their own unique way. The onset and cessation of a cluster headache is more abrupt whereas in migraine it's more gradual and lasts for $3-4$ hours minimum. Cluster headaches are always unilateral, severe sharp pain accompanied by cranial autonomic signs. In migraine the pain is on one side or travels from one side to another and is of a dull aching variety and increases during physical activity. So typically, a patient with migraine restricts his movements whereas most cluster headache sufferers seem to move around or keep rocking back and forth. Even though nausea, vomiting, photosensitivity or visual disturbances are more specific for migraine, these features have also been reported in people with $\mathrm{CH}$, especially in women, sometimes making it difficult to differentiate it in the first visit.14,15,16

\section{CONCLUSIONS}

This study helped us in estimating the incidence of cluster headache at Sri Muthukumaran Medical College Hospital and Research Institute. The study focused on primary headaches 
and not secondary. Diagnosis was mainly clinical hence history taking, and examination was of pivotal importance. ${ }^{17}$

Previous studies from India especially south, has always focused on migraine and tension type headaches and the research about cluster headache and its incidence is not as much. The limitation of the study is the small sample size compared to the population in a large and culturally diverse country like India.

\section{Abbreviations \\ $\mathrm{CH}$ - Cluster Headache, \\ ENT - Ear Nose Throat}

Data sharing statement provided by the authors is available with the full text of this article at jemds.com.

Financial or other competing interests: None.

Disclosure forms provided by the authors are available with the full text of this article at jemds.com.

\section{REFERENCES}

[1] Ahmed F. Headache disorders: differentiating and managing the common subtypes. $\mathrm{Br} J$ Pain 2012;6(3):124-32.

[2] Santos T, Morias H. Chronic cluster headache with an atypical presentation and treatment response. Case Reports in Neurological Medicine 2016;2016:4.

[3] Kernick D, Matharu MS, Goadsby PJ. Cluster headache in primary care: unmissable, underdiagnosed and undertreated. Br J Gen Pract 2006;56(528):486-7.

[4] Rozen TD, Niknam RM, Shechter AL, et al. Cluster headache in women: clinical characteristics and comparison with cluster headache in men. J Neurol Neurosurg Psychiatry 2001;70(5):613-7.

[5] Almeida RF. Cluster headache: clinical features and pathophysiology: a brief review. Migrâneascefaleias 2004;7(4):133-9.

[6] Jurno ME, Pereira BSR, Fonseca FAS, et al. Epidemiologic study of cluster headache prevalence in a medium-size city in Brazil. Arq Neuropsiquiatr 2018;76(7):467-72.
[7] Bhargava A, Pujar GS, Banakar BF, et al. Study of cluster headache: a hospital-based study. J Neurosci Rural Pract 2014;5(4):369-73.

[8] Ekbom K, Svensson DA, Traff $\mathrm{H}$, et al. Age of onset and sex ratio in cluster headache: observations over three decades. Cephalgia 2002;22(2):94-100.

[9] Friedman AP, Mikropoulos HE. Cluster headaches. Neurology 1958;8(9):653-63.

[10] Kudrow L. The cyclic relationship of natural illumination to cluster period frequency. Cephalalgia 1987;7(Suppl 6):76-8.

[11] Peng KP, Takizawa T, Lee MJ. Cluster headache in Asian populations: similarities, disparities and a narrative review of the mechanisms of the chronic sub type. Cephalalgia 2020;40(10):1104-12.

[12] Graff JM, Lee AG. Horner's syndrome (due to Cluster Headache): 46-year-old male presenting with HA and ptosis.

2005. http://www.EyeRounds.org/cases/case22.htm.

[13] Delaruelle Z, Ivanova TA, Khan S, et al. Male and female sex hormones in primary headaches. J Headache Pain 2018;19(1):117.

[14] Lance JW, Anthony M. Migrainous neuralgia or cluster headache? J Neurol Sci 1971;13(4):401-14.

[15] Haimanot RT, Seraw B, Forsgren L, et al. Migraine, chronic tension-type headache and cluster headache in an Ethiopian rural community. Cephalalgia 1995;15(6):449-50.

[16] Lund NLT, Snoer AH, Jensen RH. The influence of lifestyle and gender on cluster headache. Curr Opin Neurol 2019;32(3):443-8.

[17] Manzoni GC, Terzano MG, Bono G, et al. Cluster headache--clinical findings in 180 patients. Cephalalgia 1983;3(1):21-30.

[18] Wei DY, Yuan Ong JJ, Goadsby PJ. Cluster headache: epidemiology, pathophysiology, clinical features and diagnosis. Ann Indian Acad Neurol 2018;21(Suppl 1):S38.

[19] Leroux E, Ducros A. Cluster headache. Orphanet J Rare Dis 2008;3:20.

[20] Chakravarty A, Mukherjee A, Roy D. Trigeminal autonomic cephalgias and variants: clinical profile in Indian patients. Cephalalgia 2004;24(10):859-66. 